\title{
Stable isotope systematics of surface water bodies in the Himalayan and Trans-Himalayan (Kashmir) region
}

\author{
KANCHAN PANDE ${ }^{\dagger}$, J T PADIA, R RAMESH and K K ShARMA* \\ Physical Research Laboratory, Ahmedabad 380009 , India. \\ ${ }^{*}$ Wadia Institute of Himalayan Geology, Dehradun 248002, India. \\ ${ }^{\dagger}$ email: kanchan@prl.ernet.in
}

\begin{abstract}
Stable hydrogen $(\delta \mathrm{D})$ and oxygen $\left(\delta^{18} \mathrm{O}\right)$ isotope ratios of the headwaters of the Indus and its tributaries, surface ice in glaciers, saline and fresh water lakes and thermal springs in the Himalayan and TransHimalayan (Kashmir) region are reported. The $\delta \mathrm{D}-\delta^{18} \mathrm{O}$ relationship for the river samples shows a slope of $9.12 \pm 0.29$ which agrees well with the estimate of $8.99 \pm 0.33$ based on a simple Rayleigh fractionation model. The unique signature of a higher deuterium excess $(d)$ of the 'Western Disturbance' is preserved in these samples. An altitude effect of -0.9 per mil $/ \mathrm{km}$ is observed in the $\delta^{18} \mathrm{O}$ of Indus waters. At a lower altitude (Beas) the altitude effect is almost double, indicating that the altitude effect decreases with elevation in this region.
\end{abstract}

\section{Introduction}

Stable isotope studies on the water bodies of the Himalayan region can be useful to model the hydrological cycle and delineate sources of water to various reservoirs in this region. Such studies have been limited (Giggenbach et al 1983; Ramesh and Sarin 1992; Bartarya et al 1995). To fill this gap we have undertaken a stable isotope study of the headwaters of the Indus and its tributaries, surface ice in glaciers, fresh and saline lakes and thermal springs in the Himalaya and Trans-Himalaya (Kashmir), a hydrometeorologically significant but difficult and inaccessible region. In addition stable isotope measurements of surface water bodies help to interpret stable isotope data on other geological reservoirs (carbonates, organic matter, etc.) in terms of palaeoclimatic changes.

The area sampled (figure 1) comprises two distinct physiographic regions. The Trans Himalayan (Ladakh) region is bounded in the N-E by Tibet and is one of the most elevated regions in the world with no place being less than $3000 \mathrm{~m}$ in elevation. The joint effect of elevation and insolation on snowy mountains produces a unique and extreme climate (Raina 1977). Rainfall is very low (only $116 \mathrm{~mm} / \mathrm{yr}$ ) and the minimum temperature is $-8.5^{\circ} \mathrm{C}$ (January) and the maximum $17.4^{\circ} \mathrm{C}$ (July) (World Weather Records 1967). From November to March precipitation is in the form of snow ( $38 \%$ of the annual). There is practically no vegetation in this arid region. The Indus source water, glaciers, lakes and spring water samples belong mainly to this region. The other samples are from the lower, Himalayan region. This region is highly vegetated, experiences summer monsoon rain (in contrast to the Trans-Himalaya) and has a range of elevation from $600 \mathrm{~m}$ to $3000 \mathrm{~m}$.

\section{Sampling}

Water samples were collected during August 1991 in clean $30 \mathrm{ml}$ tightly capped polyethylene bottles. Fresh surface ice from the snouts of glaciers was collected, melted and stored in sample bottles. The lids were secured tightly to prevent evaporation

Keywords. Himalaya; springs; stable isotopes; altitude effect. 


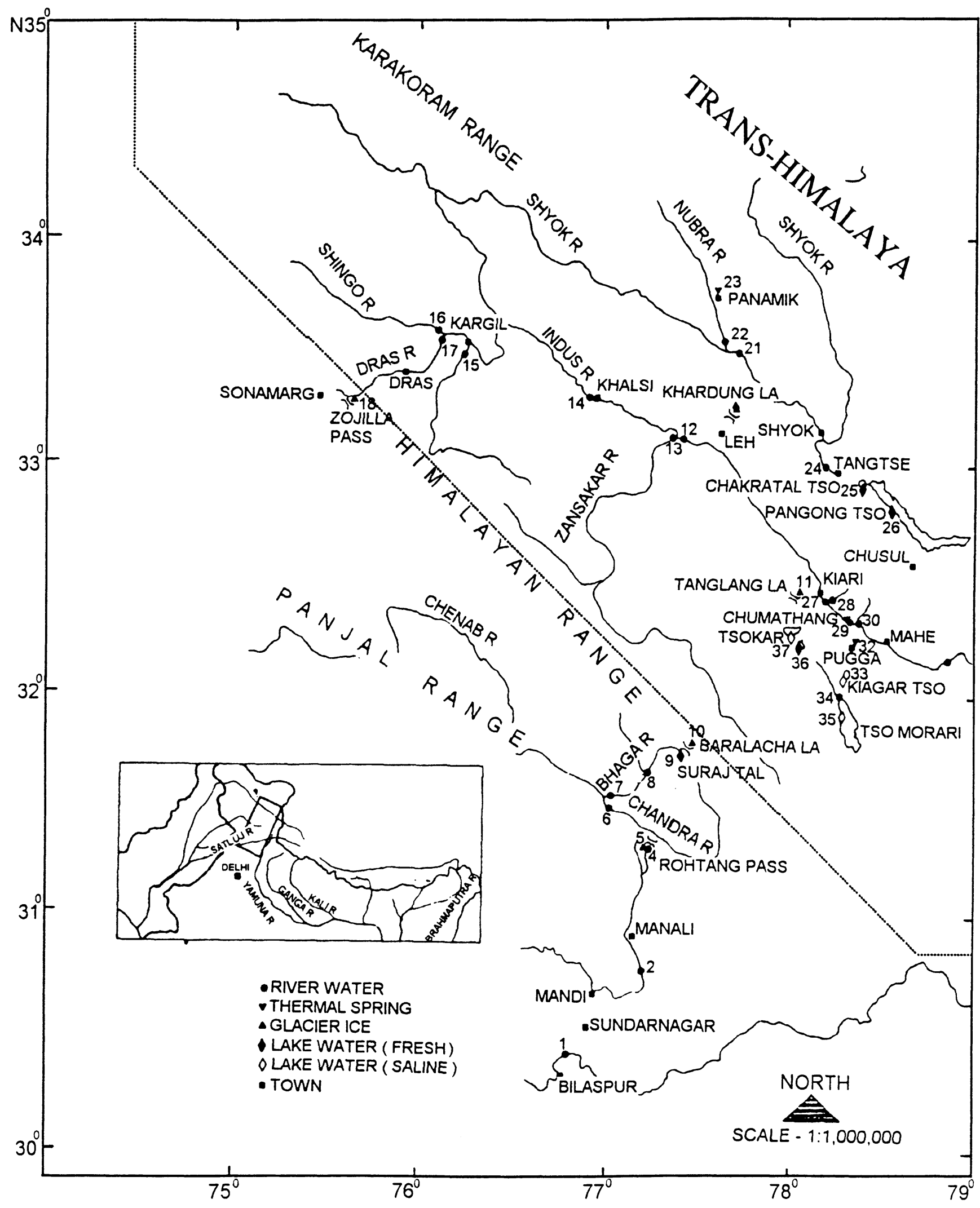

Figure 1. Map of the area sampled; numbers denote sample locations.

and exchange with the atmospheric water vapour. All samples were analysed within a month of collection. Sample numbers and locations are shown in figure 1.

\section{Analytical methods}

About $2 \mathrm{ml}$ of each sample was equilibrated with tank $\mathrm{CO}_{2}$ at $25^{\circ} \mathrm{C}$ for $48 \mathrm{~h}$ and the $\mathrm{CO}_{2}$ then extracted, 
purified and let into a VG Micromass 602D mass spectrometer (VG Analytical, Wythenshawe Manchester, UK). $\delta^{18} \mathrm{O}$ was determined with an overall precision of $\pm 0.2 \%$ opstein and Mayeda 1953). About $10 \mu \mathrm{l}$ of each sample was passed through uranium filings kept at $800^{\circ} \mathrm{C}$ and reduced to hydrogen gas, which was then transferred to 602D VG Micromass mass spectrometer for $\delta \mathrm{D}$ measurement; $\delta \mathrm{D}$ was measured with an overall precision of $\pm 1 \%$ (Friedman 1953). All values are reported relative to V-SMOW (Vienna Standard Mean Ocean Water; Gonfiantini 1981).

\section{Results and discussion}

The results are presented in table 1 . The Indus river and its tributaries have $\delta^{18} \mathrm{O}$ values in the range -11 to $-17 \%$ and $\delta \mathrm{D}$ from -70 to $-124 \%$, typical of high altitude precipitation. A plot of $\delta \mathrm{D}-\delta^{18} \mathrm{O}$ is shown in figure 2 . The 19 river water samples define a best fit line given by

$$
\delta \mathrm{D}=(9.12 \pm 0.29) \delta^{18} \mathrm{O}+(31.1 \pm 4.2)
$$

with a correlation coefficient $(r) 0.98$, significant at 0.01 level $(P)$ (dashed line). This regression was

Table 1. $\delta D, \delta^{18} O$ and deuterium excess (d) values in (\%o) relative to SMOW in rivers, lakes, glaciers and hot springs in the Kashmir Himalaya. Analytical uncertainty $\pm 0.2 \%$ for $\delta^{18} O$ and $\pm 1 \%$ for $\delta D$.

\begin{tabular}{llclll}
\hline Sample No. & Description & Altitude & $\delta^{18} \mathrm{O}$ & $\delta \mathrm{D}$
\end{tabular}

\section{Rivers}

Sutlej
Beas
Chandra
Bhaga
Darcha
Indus
Zanskar
Indus
Suru
Shingo
Dras
Shyok
Nubra
Tangtse
Indus
Indus
Indus
Indus
Samdoh

Lakes
Rohtang

Balacha La

Tanglang La

Zozilla

Khardung La

Khardung La

\section{Hot springs}

Ponamik

Chumathan

Pugga

-13.7
-11.1
-14.1
-14.7
-15.3
-14.6
-16.1
-15.2
-14.8
-13.4
-12.8
-16.2
-15.5
-15.2
-15.3
-14.3
-15.9
-15.7
-17.3

$-10.3$

$-15.7$

$-15.1$

$-1.4$

$-2.3$

$-6.3$

$-7.9$

$-6.6$

$$
\begin{aligned}
& -18.1 \\
& -15.9 \\
& -24.7 \\
& -12.2 \\
& -17.2 \\
& -15.3
\end{aligned}
$$

$-11.8$

$-26.2$

$-126 \quad-6.0$

16.8

8.2

17.6 


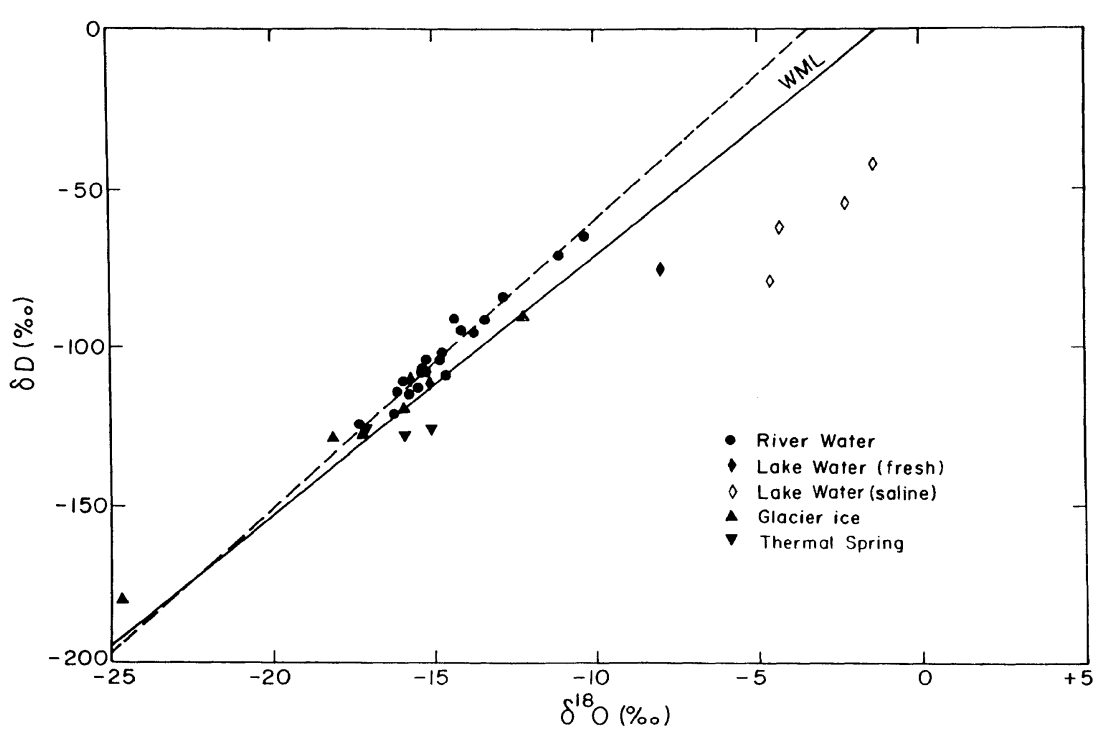

Figure 2. $\delta \mathrm{D}-\delta^{18} \mathrm{O}$ plot of samples shown in figure 1. Solid line denotes the World Meteoric Water Line (WML). Dashed line is the best fit line for the river water data only.

carried out by weighting the data points with their analytical uncertainties, following the procedure of Williamson (1968). This can be compared with the world meteoric water line (Yurtsever and Gat 1981) (WML, solid line):

$$
\delta \mathrm{D}=(8.17 \pm 0.28) \delta^{18} \mathrm{O} \pm(10.55 \pm 0.64)
$$

and that for the Ganges (Ganga) headwaters (Ramesh and Sarin 1992).

$$
\delta \mathrm{D}=(7.45 \pm 0.23) \delta^{18} \mathrm{O}+(8 \pm 2) .
$$

In the case of Trans-Himalayan rivers sampled, it is clearly seen that both the slope and the intercept are significantly higher than those of WML and Ganges (Ganga). The main reason for the slope being greater than 8 is that part of the annual precipitation falls as snow in this region and the mean annual temperature is low $\left(5.5^{\circ} \mathrm{C}\right)$. Table 2 shows the monthly precipitation and temperature data for the Trans-Himalayan Ladakh region. It is seen that for five months (November to March) the air temperature is less than or close to $0^{\circ} \mathrm{C}$. Precipitation during these months is in the form of snow (about 38\% of the total annual precipitation). If we use a simple Rayleigh Fractionation model (Gat 1981) to calculate the slope of the $\delta$ D$\delta^{18} \mathrm{O}$ relationship, in which the rate of change of $\delta$ value with respect to logarithm of the fraction of vapour left in the cloud is equal to $(\alpha-1) \times 10^{3} \%$, where $\alpha$ is the fractionation factor between liquid water and vapour [this applies for both the isotopes $\mathrm{D}$

Table 2. Model calculation of slope of the $\delta D-\delta^{18} O$ relationship based on meteorological (World Weather Records 1967$)$ and equilibrium fractionation factors (Majoube 1971) between liquid-vapour except for winter months (marked with *) where ice-vapour

\begin{tabular}{|c|c|c|c|c|c|}
\hline \multirow[b]{2}{*}{ Month } & \multirow{2}{*}{$\begin{array}{l}\text { Precipitation } \\
\quad(\mathrm{mm})\end{array}$} & \multirow{2}{*}{$\begin{array}{c}\text { Temperature } \\
\left({ }^{\circ} \mathrm{C}\right)\end{array}$} & \multicolumn{2}{|c|}{ Fractionation factors } & \multirow[b]{2}{*}{ Slope } \\
\hline & & & Deuterium & Oxygen-18 & \\
\hline January* & 12 & -8.5 & 1.148 & 1.0164 & 9.02 \\
\hline February* & 9 & -5.5 & 1.142 & 1.0160 & 8.88 \\
\hline March* $^{*}$ & 12 & 0.1 & 1.132 & 1.0152 & 8.68 \\
\hline April & 7 & 5.6 & 1.113 & 1.0113 & 10.00 \\
\hline May & 7 & 10.0 & 1.098 & 1.0107 & 9.16 \\
\hline June & 4 & 13.9 & 1.090 & 1.0101 & 8.91 \\
\hline July & 16 & 17.4 & 1.085 & 1.0098 & 8.67 \\
\hline August & 19 & 16.9 & 1.083 & 1.0100 & 8.30 \\
\hline September & 12 & 13.1 & 1.094 & 1.0103 & 9.13 \\
\hline October & 7 & 6.7 & 1.111 & 1.0111 & 10.00 \\
\hline November* & 3 & 0.6 & 1.129 & 1.0130 & 9.92 \\
\hline December* & 8 & -4.8 & 1.140 & 1.0150 & 9.33 \\
\hline $\begin{array}{l}\text { Mean } \\
\text { (or total) }\end{array}$ & 116 & 5.5 & - & - & $\begin{array}{r}8.99 \\
\pm 0.33\end{array}$ \\
\hline
\end{tabular}
fractionation is considered. 
and $\left.{ }^{18} \mathrm{O}\right]$, the slope of the $\delta \mathrm{D}-\delta^{18} \mathrm{O}$ relationship for precipitation is given by $\left(\alpha_{\mathrm{D}}-1\right) /\left(\alpha^{18} \mathrm{O}-1\right)$. The fractionation factors for the corresponding monthly temperatures are also shown in table 2 . The slope is calculated for each month and an average of all the slopes, weighted with precipitation, is found to be $8.99 \pm 0.33$, in good agreement with the observed value of $9.12 \pm 0.29$. For the period November to March we have used ice-vapour equilibrium fractionation factors while for other months we have used those of liquid water-vapour (Majoube 1971). Thus to a first order approximation, the higher than 8 slope appears to be mainly caused by the low air temperatures and snow precipitation. Rozanski et al (1993) note that for stations with substantial contribution of snow precipitation, higher deuterium excess values (discussed below) during winter may result from additional kinetic fractionation during snow formation (Jouzel and Merlivat 1984). This could also lead to a slope greater than 8 .

However, stable isotope studies of cold springs and rivers in Tapoban and Badrinath in UP Himalaya (elevation $\sim 3000 \mathrm{~m}$ ) showed a relationship

$$
\delta \mathrm{D}=7.7 \delta^{18} \mathrm{O}+13.0\left(r^{2}=0.94, n=7\right)
$$

(Navada et al 1985). In similar high altitude stations elsewhere in the world (e.g. Ecuador 3058 m, Columbia $2547 \mathrm{~m}$ and Adis Ababa $2360 \mathrm{~m}$ ) the slopes are either 8 or slightly less. Therefore our results could be specific to the Ladakh region only.

We examine the deuterium excesses parameter $(d)$ defined as $\delta \mathrm{D}-8 \delta^{18} \mathrm{O}$, shown in table 1 . As about $38 \%$ of the annual precipitation is derived from westerlies ('Western Disturbance') whose source is the Mediterranean Sea (Raina 1977) with a characteristically higher deuterium excess (Gat and Carmi 1970) the river water samples also exhibit higher deuterium excess. The average $d$ value is $14.7 \pm 3.1 \%$. All along the path of the Western Disturbance (Iran, Afghanistan, Pakistan and Kashmir) the precipitation is characterised by high deuterium excess (Yurtsever and Gat 1981). In a compilation of deuterium excess data from precipitation samples collected world wide, Rozanski et al (1993) found that between $30^{\circ}$ and $40^{\circ} \mathrm{N}$, most samples show high deuterium excess (in the range 15 to 25 per mil). Thus the high values of deuterium excess in our samples confirm the findings of Rozanski et al (1993), who also showed that the increase of the deuterium excess was correlated with the seasonal bias of precipitation towards winter. High deuterium excess values $(\sim 13.00 \pm 3.29 \%)$ have also been reported from Parbati Valley ground and cold spring waters (Giggenbach et al 1993).

The enhanced $d$ values could also be due partly to a contribution of moisture from evaporation from local water bodies to the cloud formation. Such local evaporation can occur from fresh and salt water lakes in this arid region. Figure 2 shows that samples from

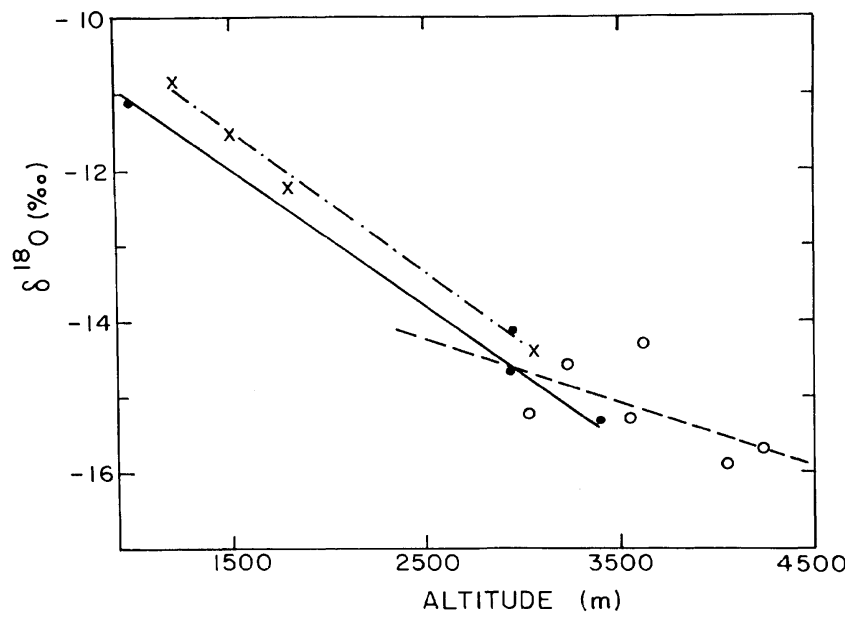

Figure $3 . \delta^{18} \mathrm{O}$ as a function of altitude; solid line - Beas (filled circles); dashed line - Indus (open circles); dashed dotted line Ganges main channel (crosses) (data from Ramesh and Sarin 1992).

the four saline lakes and one fresh water lake (Sputtsong Tso) plot well below the local meteoric line and WML indicating that these have undergone significant evaporation. The point of intersection of the best fit line for these points with the best fit line for the river water samples gives an approximate estimate of their original isotopic composition. It can therefore be estimated that annual evaporation could be as high as $70 \%$ of the annual precipitation in these lakes (estimate based on Rayleigh isotopic fractionation model taking into account the $\delta^{18} \mathrm{O}$ atmospheric water vapour). Further, the six glacier snout ice samples also show a reduced slope (line not shown in figure 2): $\delta \mathrm{D}=(7.29 \pm 0.19) \delta^{18} \mathrm{O}+(0.4 \pm 3.4)$ with $r=0.99, P=0.01$ suggestive of sublimation of ice and local contribution of moisture to the clouds.

Figure 3 shows a plot of $\delta^{18} \mathrm{O}$ of some of the samples as a function of altitude. As different rivers in this region (Beas, Sutlej and Indus) receive their water from different source regions, it is possible to detect the altitude effect only along the main channel of a single river. For the Indus river (open circles) in the Trans-Himalaya, the equation is

$$
\delta^{18} \mathrm{O}=-(0.086 \pm 0.011) \text { alt }-(12.07 \pm 0.41)
$$

with $r=-0.58 P=0.01$

where alt is altitude in units of $100 \mathrm{~m}$.

For Beas,

$$
\delta^{18} \mathrm{O}=-(0.17 \pm 0.01) \text { alt }-(9.39 \pm 0.16)
$$

with $r=-0.99 \mathrm{P}=0.01$.

Thus the altitude effect for Indus (Trans Himalaya) is about $-0.09 \%$ for $100 \mathrm{~m}$ whereas for Beas (Himalaya) it is $-0.17 \%$ per $100 \mathrm{~m}$, comparable to that for Ganges (Ramesh and Sarin 1992). Giggenbach et al (1983) in an isotope study of hot and cold springs in the Parbati Valley, Himachal Pradesh, report an 
altitude effect of $-1 \%$ per $\mathrm{km}$ for cold springs. This is similar in magnitude to the value observed by us for the Indus river data.

It has been shown that the "altitude effect" in Ganges river water samples is about half that in precipitation in the source region of Ganges (Ramesh and Sarin 1992) due to the averaging of the $\delta^{18} \mathrm{O}$ values as the river picks up water at different altitudes during its descent. A similar conclusion is valid for the Beas samples. However, for the Indus samples (higher altitude compared to Beas) the altitude effect is about half that seen for Beas. The reason could be that the altitude effect rapidly decreases with elevation in this region. It has been shown that $\delta^{18} \mathrm{O}$ in fresh snow from Garhwal does not show any altitude effect in the range 4400 to $6050 \mathrm{~m}$ (Niewodniczanski et al 1981). Our results are consistent with their finding. Another possible explanation would be as follows : Most of the air masses come south and as they are rising on the southern slope of Himalaya, the vapour condenses and produces precipitation. When the top elevation is reached there is not much vapour left (and therefore the northern slope is arid) and the influence of altitude on the condensation process and isotopic composition of precipitation becomes negligible. This phenomenon has also been observed in Gran Canaria, Canary Islands (Gonfiantini et al 1976). Therefore the small altitude effect could be mainly due to evaporation during rainfall. According to another view (Navada, personal communication) the Indus during its descent may not be picking up much water and this could be a cause of the reduced altitude effect.

Mayewski and Lyons (1983) reported $\delta \mathrm{D}$ data for 8 snow samples from Zanskar between 5100 and $5500 \mathrm{~m}$ elevations. Our glacier samples show similar values (table 1). Giggenbach et al (1983) reported $\delta \mathrm{D}, \delta^{18} \mathrm{O}$ values for 3 snow samples from an altitude range $3400 \sim 3800 \mathrm{~m}$ in Himachal Pradesh. Their values are enriched by an average of $10 \%$ in $\delta^{18} \mathrm{O}$ and $80 \%$ in $\delta \mathrm{D}$ compared to the glacier samples reported in table 1 (from the altitude range 3500 to $5600 \mathrm{~m}$ ) indicating substantial amount of high altitude snow precipitation in our samples. Likewise, the isotopic composition of thermal springs are also lower (by the same magnitude) than those of the hot springs from Parbati Valley (Giggenbach et al 1983) and Nepal (Grabczak and Kotarba 1985). This indicates that the former are being recharged by precipitation from higher altitudes.

\section{Conclusion}

We have reported $\delta \mathrm{D}, \delta^{18} \mathrm{O}$ data for the Himalayan and Trans-Himalayan water bodies including Indus river and its tributaries. The Indus waters have a higher than normal slope in the $\delta \mathrm{D}-\delta^{18} \mathrm{O}$ plot as the precipitation in this region is partly in the form of snow and the mean annual temperature is in general low. The theoretically calculated slope is in good agreement with the observed value. Also, these samples have in general higher deuterium excess values indicating that they preserve the signature of 'Western Disturbance'. The altitude effect in this region decreases with elevation.

\section{Acknowledgements}

It is a great pleasure to contribute this paper to the Prof. K Gopalan special issue. Prof. Gopalan set up the first stable isotope laboratory at PRL, Ahmedabad in 1978 and initiated several programmes on isotope hydrology. Partial financial support by Department of Science and Technology, Govt. of India, to one of us (KKS) is gratefully acknowledged. We benefitted by review from $\mathrm{R}$ Gonfiantini and an anonymous reviewer.

\section{References}

Bartarya S K, Bhattacharya S K, Ramesh R and Somayajulu B $\mathrm{L} \mathrm{K} 1995 \delta^{18} \mathrm{O}$ and $\delta \mathrm{D}$ systematics in the surficial waters of the Gaula river catchment area, Kumaun Himalaya, India; J. Hydrology 167 369-379

Epstein S and Mayeda T 1953 Variation of $\delta^{18} \mathrm{O}$ content in waters from natural sources; Geochim. Cosmochim. Acta 4 $213-224$

Friedman I 1953 Deuterium content of natural waters and other substances; Geochim. Cosmochim. Acta 4 89-103

Gat J R and Carmi I 1970 Evolution of the isotopic composition of atmospheric waters in the Mediterranean sea area; J. Geophys Res, 75 3039-3048

Gat J R 1981 In Stable Isotope Hydrology (eds.) J R Gat and R Gonfiantini, IAEA Tech. Rep. Ser. 210 7-19

Giggenbach W F, Gonfiantini R, Jangi B L and Truesdell A H 1983 Isotopic and chemical composition of Partabi Valley geothermal discharges, north-west Himalaya, India; Geothermics 12(2/3) 199-222

Gonfiantini R, Gallo G, Payne B R and Taylor C B 1976 Environmental isotopes and hydrochemistry in ground water of Gran Canaria. In: Interpretation of environmental isotope and hydrochemical data in ground water hydrology pp 159170 Vienna: IAEA

Gonfiantini R 1981 In: Stable Isotope Hydrology (eds) J R Gat and R Gonfiantini, IAEA Tech Rep Ser 210 35-85

Grabczak J and Kotarba M 1985 Isotopic composition of the thermal waters in the central part of the Nepal Himalayas; Geothermics 14(4) 567-575

Jouzel J and Merlivat L 1984 Deuterium and oxygen 18 in precipitation: Modelling of the isotopic effect during snow formation; J. Geophys. Res. 89 11749-11757

Majoube M 1971 Fractionnement en oxygene 18 et en deuterium entre l'eau et sa vapeur; J. Chim. Phys. 10 1423-1436

Mayewski P A and Lyons W B 1983 Chemical composition of a high altitude fresh snow fall in the Ladakh Himalayas; Geophys. Res. Lett. 10(1) 105-108

Navada S V, Nair A R, Sharma S and Kulkarni U P 1985 Geochemical and Isotope studies of the geothermal areas of central and northern India; Isotope and geochemical techniques applied to geothermal investigations. (IAEATECDOC-) $\mathbf{7 8 8} 63-82$ 
Niewodniczanski J, Grabczak J, Baranski L and Rzepka J 1981 The altitude effect on the isotopic composition of snow in higher mountains; J Glaciol 27 99-112

Raina A N 1977 Geography of Jammu and Kashmir (New Delhi: National Book Trust) $271 \mathrm{p}$

Ramesh R and Sarin M M 1992 Stable isotope study of the Ganges (Ganga) river system; J. Hydrol. 139 49-62

Rozanski K, Arguas L A and Gonfiantini R 1993 Isotopic patterns in modern global precipitation; In: Climate change in continental isotopic indicators geophys mon $78 \mathrm{Am}$. Geophys. Union 1-36

Williamson J H 1968 Least square fitting of a straight line; Can. J. Phys. 46 1845-1847

World Weather Records 1967 Washington DC: U.S. Dept. of Commerce 4372

Yurtsever Y and Gat J R 1981 In: Stable isotope hydrology (eds) J R Gat and R Gonfiantini (IAEA Tech Rep Ser) 210 103-142 